\title{
Simulasi dan Eksperimental Isothermal Aliran Eksternal Resirkulasi pada Up-Draft Gasifier
}

\author{
Fajri Vidian, Hery Prabowo, Adi Surjosatyo, dan Yulianto Sulistyo Nugroho \\ Departemen Teknik Mesin, Fakultas Teknik, Universitas Indonesia, Depok \\ Email: adi.surjosatyo@ui.ac.id
}

\begin{abstract}
ABSTRAK
Proses gasifikasi pada updraft gasifier menghasilkan jumlah tar yang lebih besar dibandingkan dengan type gasifier yang lain. Untuk mengurangi tar pada updraft gasifier maka dilakukan resirkulasi gas pirolisa ke daerah pembakaran dan pengeluaran gas dari daerah reduksi. Resirkulasi gas pirolisa ke daerah pembakaran dapat dilakukan dengan menggunakan ejektor. Ejektor adalah peralatan yang di gunakan mendorong aliran fluida sekunder oleh perpindahan momentum dan energi dari aliran primer berkecepatan tinggi (jet). Metode penelitian yang dilakukan adalah simulasi isothermal 3D menggunakan CFD dan eksperimental aliran resirkulasi pada updrat gasifier menggunakan ejektor. Simulasi dan eksperimental dilakukan dengan kecepatan aliran udara pada ejektor di jaga kosntan $0.6 \mathrm{~m} / \mathrm{s}$ dengan memvariasikan posisi arah gerakan keluaran nozel ejektor. Penelitian ini bertujuan mendapatkan informasi posisi keluaran nozel dari ejektor yang optimum untuk menghasilkan kecepatan aliran resirkulasi yang maksimum pada updraft gasifier menggunakan ejector melalui simulasi dan eksperimental. Hasil simulasi dan eksperimental memperlihatkan perubahan posisi keluaran nozel ke arah sumbu $\mathrm{x}$ negatif dari titik nol akan memberikan peningkatan kecepatan aliran resirkulasi dimana posisi optimum terjadi pada keluaran nozel -3 $\mathrm{cm} \mathrm{s} / \mathrm{d}-4 \mathrm{~cm}$ dari titik nol (arah sumbu x negatif).
\end{abstract}

Kata kunci: Simulasi, eksperimental, isothermal, resirkulasi, updraft gasifier.

\begin{abstract}
Gasification process at updraft gasifier produces greater amount of tar than other type of gasifier. To reduce tar at updraft gasifier, the pirolysis gas will be re-circulated to combustion zone and to exhaust gas from reduction zone. Recirculation of pirolysis gas to combustion zone can be carried out by using ejector. Ejector is an equipment used to inject the secondary fluid flow by the movement of momentum and energy from high speed primary flow (jet). The research conducted with isothermal $3 D$ simulation using CFD and experimental investigation of recirculation flow using ejector at updraft gasifier. Ejector velocity for simulation and experimentation is constant at $0.6 \mathrm{~m} / \mathrm{s}$. Ejector's nozzle exit position (NXP) direction will be varied. The goal of this research is to obtain information of optimal nozzle exit position for producing maximum velocity of gas recirculation. The result of simulation and experiment shows that the change of nozzle exit position direction to $-x$ axis from zero point, it will give maximum velocity of gas recirculation flow with the optimum position of nozzle exit position at the range of -3 to $-4 \mathrm{~cm}$ from zero point.
\end{abstract}

Keywords: Simulation, experimental, isothermal, resirculation, updraft gasifier.

\section{PENDAHULUAN}

Proses gasifikasi pada updraft gasifier memiliki keungulan pada pengoperasian yang sederhana, pengkonversian karbon yang tinggi, efisiensi yang lebih tinggi, kontinuitas gas lebih stabil, kandungan air bahan bakar $>60 \%$, fleksibel terhadap bermacam bentuk ukuran biomassa dan lebih mudah dalam scale up di bandingkan downdraft gasifier [1]. Akan tetapi type updraft gasifier memiliki kandungan tar yang tinggi.

Dalam usaha untuk menggurangi tar pada updraft gasifier maka dilakukan pengembangan metode resirkulasi gas pirolisa ke daerah pembakaran dan pengeluaran gas dari daerah reduksi pada updraft gasifier. Resirkulasi gas pirolisa ke 
daerah pembakaran bertujuan untuk mengurangi tar melalui penguraian (cracking) dan pembakaran parsial (partial combustion) pada daerah pembakaran bertemperatur tinggi. Salah satu metode yang digunakan untuk meresirkulasikan gas adalah menggunakan ejektor. Penggunaan ejektor banyak keuntungannya yaitu reability, biaya operasi rendah, instalasi sederhana dan ramah lingkungan.

Untuk mendapatkan informasi aliran resirkulasi pada updraft gasifier menggunakan ejektor dan posisi keluaran nozel (NXP) yang optimum yang menghasilkan kecepatan aliran maksimum maka dilakukan studi awal melalui simulasi aliran dingin menggunakan CFD kemudian dibandingkan dengan hasil eksperimental.

Pada simulasi dan eksperimen ini hanya difokuskan untuk mendapatkan informasi penggunaan ejektor dapat menarik aliran dari bagian atas reaktor ke daerah bagian bawah reaktor dan pengaruh perubahan posisi keluaran nozel terhadap kecepatan maksimal aliran resirkulasi. Pada proses gasifikasi gas hasil proses pirolisa akan naik terlebih dahulu keatas sebelum menuju saluran keluar, gas inilah yang diasumsikan sebagai udara yang dihembus dari bawah sehingga perlu diasumsikan reaktor kosong. Simulasi dan eksperimen ini belum mempertimbangkan hambatan bahan bakar terhadap karakteristik aliran resirkulsi. Untuk melihat karakteristik kemampuan motive flow mendorong aliran sekunder melewati bahan bakar maka model simulasi dan eksperimen yang akan dilakukan berbeda yaitu motive flow menarik aliran sekunder dari udara bebas tampa ada aliran udara yang dihembus kedalam reaktor dari bagian bawah reaktor sehingga akan terlihat jumlah aliran sekunder yang dapat di tarik oleh motive flow tertentu dengan posisi keluaran nozel (NXP) didapat pada penelitian ini.

Beberapa penelitian telah dilakukan untuk mengoptimasi posisi keluaran nozel (nozzle exit position) pada sistem ejektor menggunakan CFD. Riffat dkk [2] melakukan simulasi pengaruh posisi keluaran nozel terhadap ejector performace menggunakan model turbulensi standard dan RNG kepsilon, hasil penelitian menunjukkan posisi gerakkan nozel arah sumbu x negatif memberikan hasil yang maksimum. K Pianthong dkk [3] melakukan simulasi menggunakan CFD untuk melihat pengaruh posisi keluaran nozel terhadap fenomena aliran dan performance pada constan pressure area (CPA) ejector dan constan mixing area (CMA) dengan menggunakan model turbulensi realizable turbulen $\mathrm{k}$ - epsilon, hasil penelitian menunujukkan posisi gerakkan nozel arah sumbu x negatif memberikan hasil yang maksimum. Zhang dkk [4] melakukan simulasi menggunakan model turbulensi $\mathrm{RNG}-\mathrm{k}$ epsilon dan eksperimental untuk melihat pengaruh posisi keluaran nozel pada subsonic ejektor terhadap jumlah aliran sekunder yang dapat ditarik oleh aliran primer, hasil penelitian menunjukkan posisi gerakkan sumbu $\mathrm{x}$ negative dari titik 0 memberikan hasil yang maksimum.

Penelitian ini bertujuan untuk mendapatkan informasi posisi keluaran nozel yang optimum yang dapat menghasilkan kecepatan aliran resirkulasi maksimum pada updraft gasifier menggunakan ejektor melalui simulasi mengunakan CFD dan eksperimental.

\section{METODE PENELITIAN}

Sebelum dilakukan simulasi maka terlebih dahulu dilakukan pembuatan gambar tiga dimensi reaktor updraf gasifier. Prinsip kerja reaktor yang akan disimulasikan dapat dijelaskan sebagai berikut. Udara utama pembakaran adalah udara 1 masuk dari bagian bawah reactor. Udara 2 adalah udara primer ejektor atau motive flow yang digunakan untuk menarik udara resirkulasi dari bagian atas ke bagian bawah reaktor. Udara keluar dari bagian kanan reaktor seperti yang di perlihatkan pada Gambar 1.

Dimensi reaktor adalah sebagai berikut: tinggi reaktor $60 \mathrm{~cm}$, diameter $20 \mathrm{~cm}$, diameter saluaran udara1, saluran udara keluar dan saluran resirkulasi masing-masing $5 \mathrm{~cm}$. Ejektor yang digunakan adalah ejektor dengan type area percampuran constan (constan mixing area) dengan tipe nozel yang digunakan adalah type convergent. Adapun model ejektor yang di gunakan diperlihatkan pada Gambar 1.

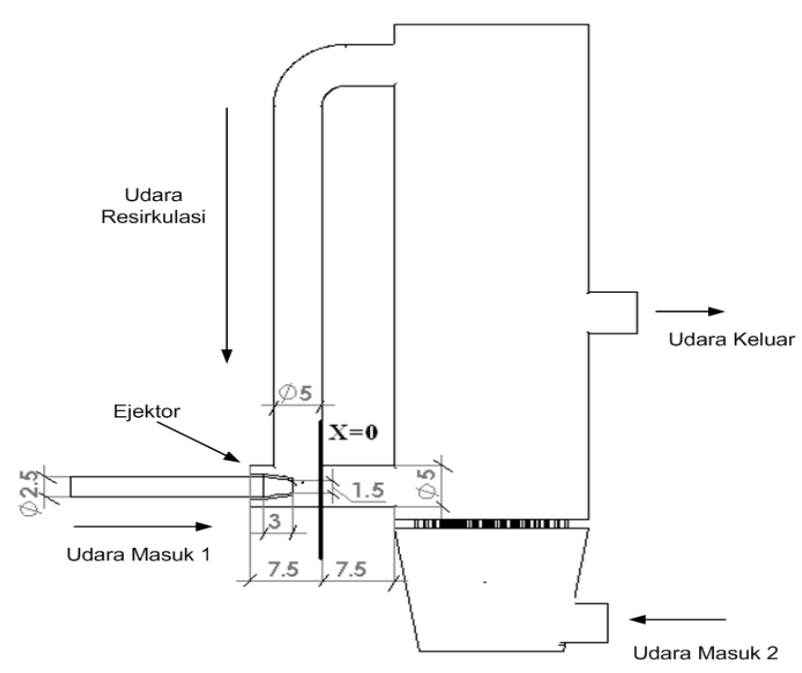

Gambar 1. Model Reaktor dan Ejektor (semua ukuran dalam cm)

Model reaktor berbentuk solid selajutnya dilakukan meshing. Type mesh yang digunakan adalah tetrahybrid seperti yang diperlihatkan pada Gambar 2. 


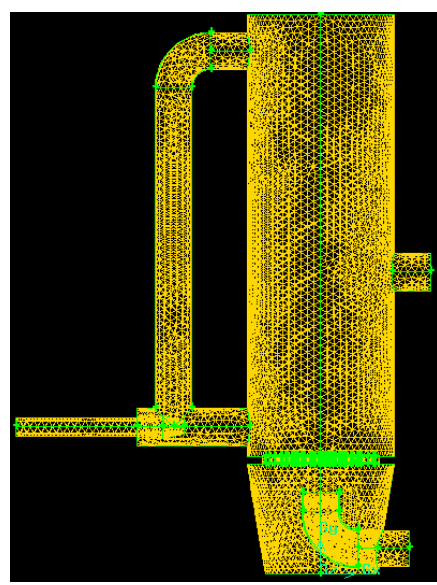

Gambar 2. Meshing Reaktor

Simulasi dilakukan menggunakan software fluent dengan menerapkan persamaan-persamaan konservasi massa, konservasi momentum, dan konservasi energi. Model turbulensi yang digunakan adalah turbulensi standar k-epsilon.

Setelah melakukan pemodelan proses untuk simulasi maka selanjutnya dilakukan penentuan kondisi batas simulasi dimana kondisi batas yang digunakan adalah kecepatan masuk (velocity inlet) untuk aliran udara masuk 1 dan aliran udara masuk 2, tekanan keluar (pressure outlet) aliran udara keluar. nilai kondisi batas yang digunakan sebagai berikut :

1. Kecepatan udara melalui bagian bawah atau udara 1 sebesar $1,2 \mathrm{~m} / \mathrm{s}$ (140 liter per menit)

2. Kecepatan udara melalui ejektor atau udara 2 sebesar $0,6 \mathrm{~m} / \mathrm{s}$ (20 liter per menit)

3. Udara keluar dengan tekanan atmosferik 1 bar

Simulasi dilakukan pada beberapa kondisi dengan kecepatan di jaga konstan.

1. Simulasi menggunakan saluran resirkulasi tampa ejektor dengan laju aliran udara dari bagian bawah sebesar 160 liter per menit

2. Simulasi menggunakan saluran resirkulasi dengan ejektor dengan variasi posisi keluaran nozel (Nozel Exit Position/NXP) dalam arah sumbu $\mathrm{x}$ positif dan $\mathrm{x}$ negatif seperti yang di perlihatkan pada Gambar 3.

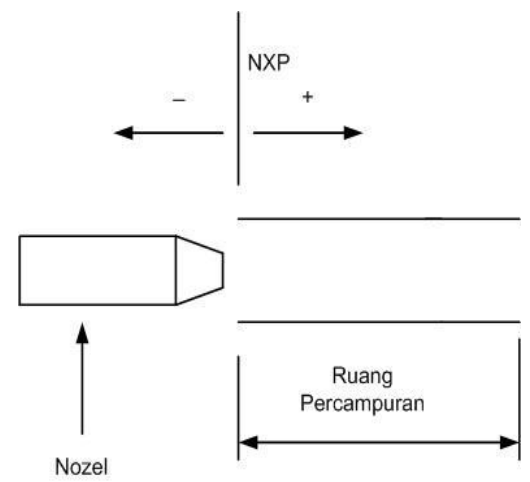

Gambar 3. Perubahan Posisi Nozel

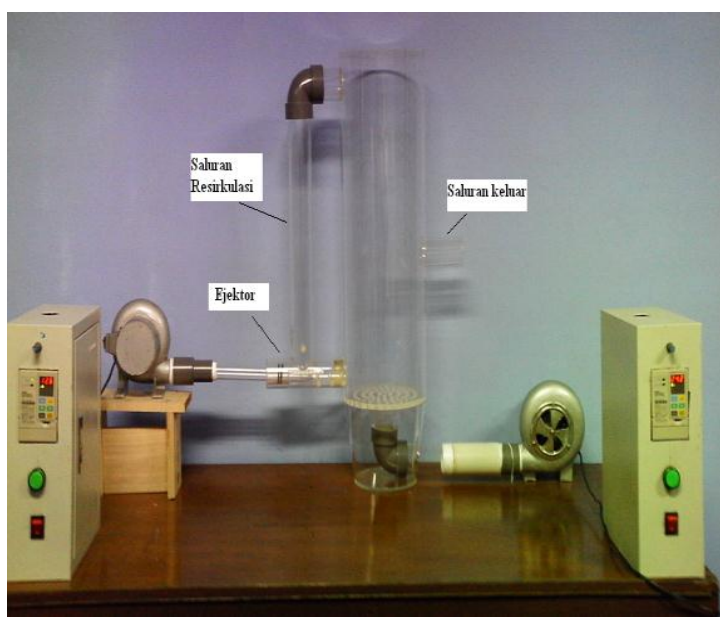

Gambar 4. Experimental Set Up

Untuk membandingkan data hasil simulasi maka dilakukan eksperimental menggunakan reaktor seperti di perlihatkan pada Gambar 4, aliran udara 1 dan 2 disuplai menggunakan blower dengan tekanan $200 \mathrm{~Pa}$ dengan kapasitas aliran udara maksimum $1036 \mathrm{lpm}$, kecepatan udara pada saluran resirkulasi diukur menggunakan hot wire anemometer dengan range pengukuran 0,1 s/d 20 $\mathrm{m} / \mathrm{s}$. Skala pembacaan untuk hot wire anemometer adalah $0,1 \mathrm{~m}$. Kecepatan aliran pada pusat saluran rensirkulasi di ukur pada posisi $5 \mathrm{~cm}$ diatas saluran atau ruang percampuran

\section{HASIL DAN PEMBAHASAN}

\section{Aliran Resirkulasi Tampa Ejektor}

Dari informasi kontur kecepatan yang didapat dari simulasi menggunakan saluran resirkulasi ekternal tanpa menggunakan ejektor seperti pada Gambar 5, kecepatan aliran resirkulasi mendekati nol. Hampir tidak ada aliran resirkulasi yang terjadi.
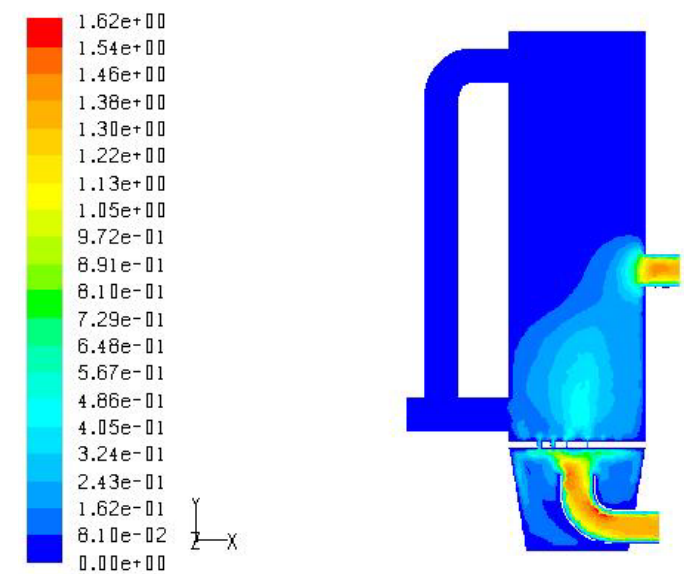

Gambar 5. Kontur Kecepatan (m/s) Aliran Udara dalam Reaktor dengan Saluran Resirkulasi tampa Ejektor 


\section{Aliran Resirkulasi Menggunakan Ejektor}

Dari hasil simulasi menggunakan ejektor seperti pada Gambar 6, kecepatan maksimum aliran resirkulasi yang dihasilkan antara $0.2 \mathrm{~s} / \mathrm{d} 0.25$ $\mathrm{m} / \mathrm{s}$. Peningkatan kecepatan disebabkan oleh adannya kecepatan jet dari motive flow pada ejector yang membuat daerah bertekanan sangat rendah disekitar ejektor, daerah bertekanan sangat rendah ini membuat fluida sekunder dalam hal aliran yang akan bersirkulasi yang tekanan awalnya tinggi (tekanan atmosfir) tertarik oleh aliran motive flow ejektor yang selanjutnya terjadi transfer momentum pada ruang percampuran.

Gambar 7, 8 dan 9 memperlihatkan distribusi kecepatan aliran resirkulasi pada saat memasuki ruang percampuran dimana terlihat pada posisi arah gerakkan nozel menuju sumbu x negatif mulai dari posisi nol terlihat distribusi kecepatan yang sama pada saluran resirkulasi akan tetapi pada arah gerakkan nozel menuju sumbu x positif terlihat adannya pengurangan kecepatan mendekati nol pada aliran resirkulasi saat memasuki ruang percampuran. Hal ini disebabkan perbedaan tekanan yang disebabkan oleh aliran motive flow tidak mampu untuk menarik aliran sekunder menuju proses percampuran antara aliran primer dan sekunder.
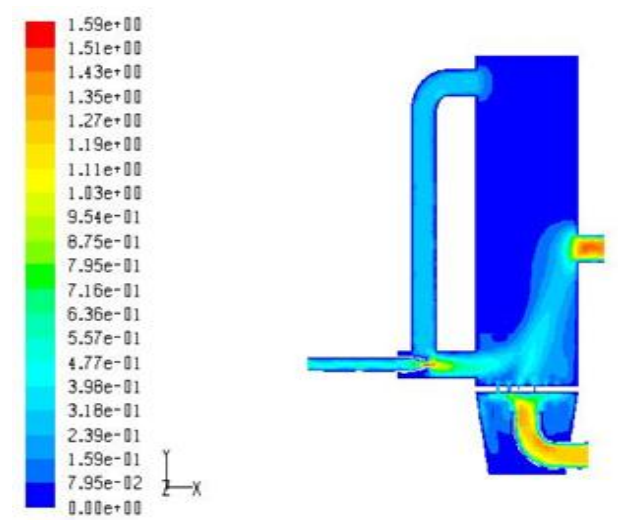

Gambar 6. Kontur kecepatan $(\mathrm{m} / \mathrm{s})$ Aliran Udara dalam Reaktor dengan Saluran Menggunakan ejektor

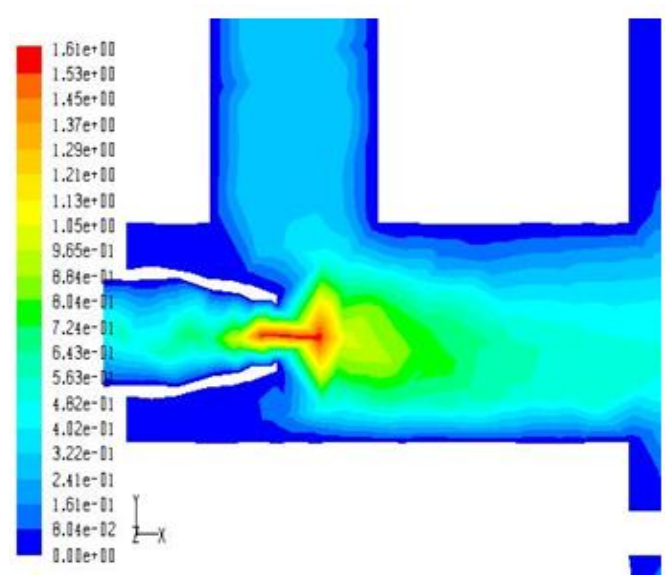

Gambar 7. Kontur Kecepatan pada Daerah nozel pada NXP-3

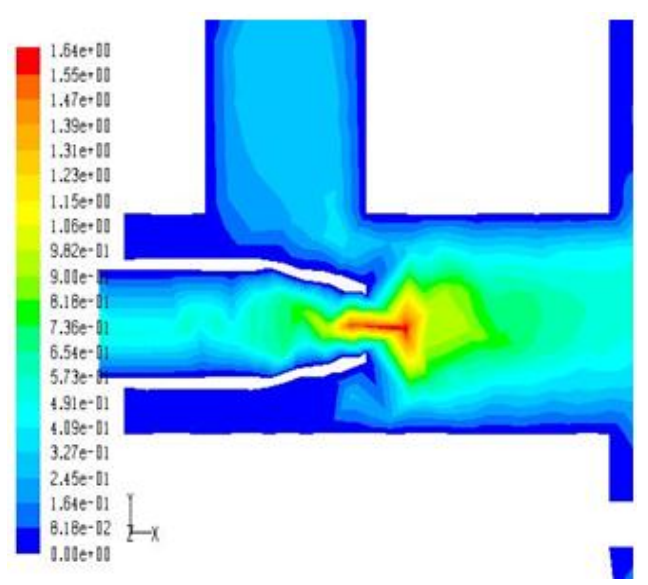

Gambar 8. Kontur Kecepatan pada Daerah nozel pada NXP 0

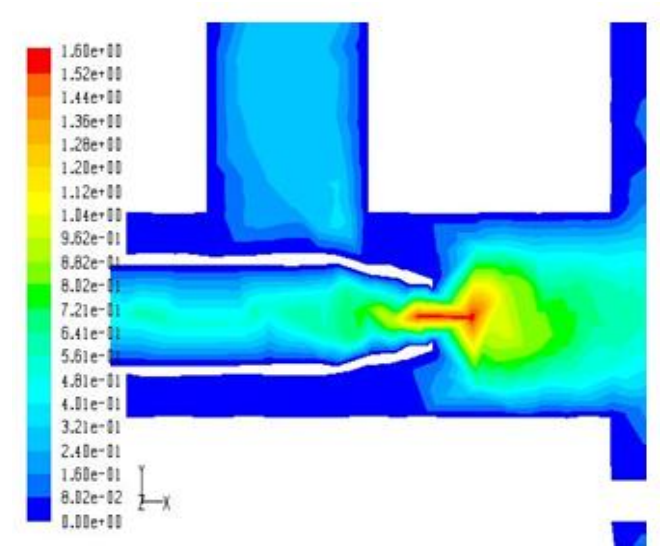

Gambar 9. Kontur Kecepatan pada Daerah Nozel pada NXP +2

\section{Perbandingan hasil simulasi dan eksperimen}

Hasil simulasi dan eksperimen untuk kecepatan aliran pada pusat saluran resirkulasi yang diukur pada titik $5 \mathrm{~cm}$ diatas ruang percampuran seperti pada Gambar 10 dimana memperlihatkan kecenderungan yang sama, semakin nozel digerakkan kearah negatif akan memberikan peningkatan kecepatan aliran resirkulasi.

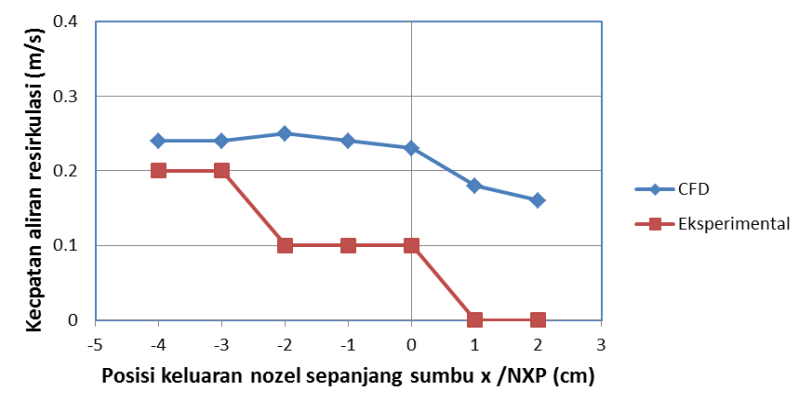

Gambar 10. Perbandingan CFD dan Eksperimen untuk kecepatan resirkulasi $(\mathrm{m} / \mathrm{s})$

Pada simulasi pengaruh perubahan posisi keluaran nozel dari arah sumbu x positif menuju sumbu x negatif memperlihatkan nilai kecil sekali 
terhadap kecepatan aliran resirkulasi akan tetapi pada eksperimen pengaruhnya sangat besar. Hal ini dikarenakan pada simulasi untuk arah gerakkan keluaran nozel pada sumbu x positif seperti pada Gambar 9 dimana terlihat kecepatan aliran pada saat memasuki ruang percampuran kecil sekali mendekati nol, kondisi ini sesuai dengan teori freejet yang dapat diterapkan pada kasus aliran pada ejektor $[4,5,6]$ untuk melihat pengaruh jarak posisi keluaran nozel dengan daerah masuk ruang percampuran $(\mathrm{H})$ terhadap panjang ruang percampuran (L) seperti pada Gambar 11a, dimana ,jika arah gerakkan nozel kearah posisi sumbu x postif ( nilai $\mathrm{H}$ semakin kecil dibawah nilai L maka aliran akan bercampur sebagian atau tidak sampai selesai di ruang percampuran sehingga jumlah aliran sekunder akan berkurang. Hal ini disebabkan adannya konstrain dari dinding ruang percampuran sehingga daerah penghisapan aliran sekunder berkurang seperti di perlihatkan pada Gambar 11b, jika dibandingkan dengan posisi $\mathrm{H}$ yang optimum dibelakang titik 0 , dimana aliran sekunder tidak terhadang oleh dinding seperti pada Gambar 11c, selain itu semakin $\mathrm{H}$ mendekati titik 0 maka akan terjadi pengaruh pencekikkan (throatling) yang lebih besar yang akan menyebabkan meningkatnya tahanan aliran sekunder memasuki daerah percampuran [4].

Kondisi ini menyebabkan pada eksperimental untuk posisi arah gerakkan menuju sumbu x positif dari titik 0, aliran primer (motive flow) tidak dapat menarik aliran resirkulasi (aliran sekunder) sehingga kecepatan pada saluran resirkulasi adalah kecil seperti yang ditunjukkan pada hasil eksperimen yaitu 0 .

Pada hasil simulasi terlihat kondisi yang ideal dimana untuk posisi arah gerakkan nozzel dari sumbu x positif menuju sumbu x negatif dari titik 0 , terlihat kecepatan aliran resirkulasi pada saluran resirkulasi hampir sama tingginnya walaupun kenyataanya pada saat posisi gerakkan nozzel menuju sumbu $\mathrm{x}$ positif dari titik 0 kecepatan aliran resirkulasi atau aliran sekunder saat memasuki ruang percampuran kecil sekali seperti diperlihatkan pada Gambar 9. Pada hasil eksperimental untuk arah gerakkan menuju sumbu x positif dari titik 0, maka kecepatan aliran resirkulasi pada saluran resirkulasi dan saat memasuki ruang percampuran sama kecilnya.

Perbedaan hasil simulasi dan eksperimental juga disebabkan perubahan parameter aliran seperti suhu dan tekanan, pada simulasi adalah kondisi ideal dimana suhu dan tekanan konstan akan tetapi pada kondisi eksperimen parameter aliran ini akan berubah-rubah sehingga kecepatan juga berubah.

Hasil eksperimen dan simulasi memberikan informasi posisi keluaran nozel (NXP) pada arah -4 dan $-3 \mathrm{~cm}$ dari titik 0 (titik awal memasuki daerah percampuran) memberikan kecepatan aliran resirkulasi yang maksimum. Hal ini dikarenakan gerakkan nozel kearah sumbu x negatif dari titik 0 akan lebih menurunkan tekanan disekitar ejektor yang mengakibatkan aliran sekunder akan lebih banyak tertarik oleh aliran primer menuju proses percampuran sehingga kecepatan aliran sekunder ikut meningkat, selain itu bertambahnya juga luasan daerah aliran sekunder yang bercampur dengan aliran primer hingga transfer momentum dari aliran primer bertambah untuk menarik aliran sekunder yang selanjutnya meningkatkan kecepatan aliran sekunder pada saluran resirkulasi.

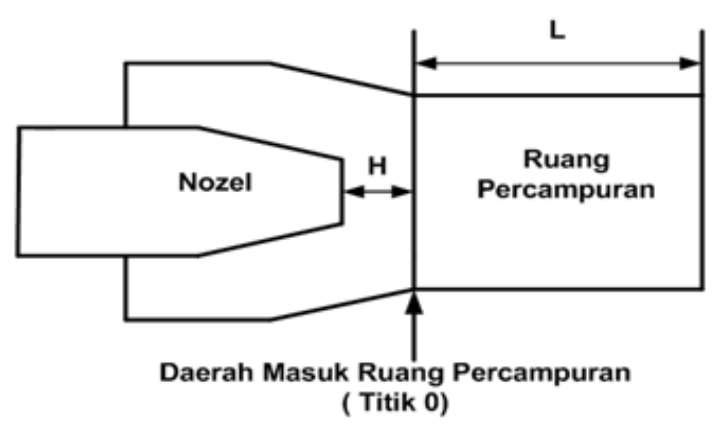

(a) Jarak Keluaran Nozel terhadap titik $\mathrm{O}(\mathrm{H})$

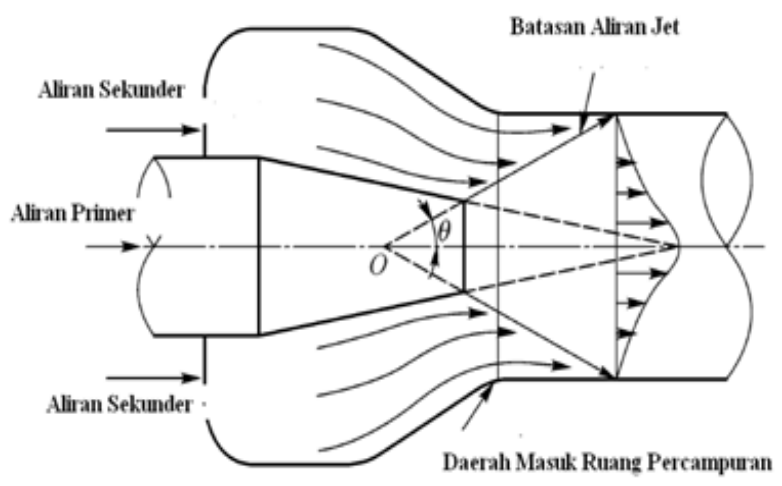

(b) Posisi Keluaran Nozel (H) mendekati titik 0 (arah positif)

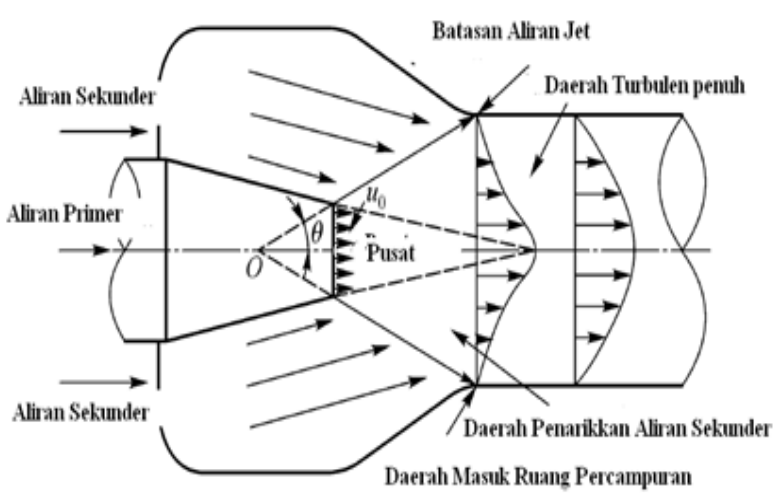

(c) Posisi keluaran Nozel menjauhi titik 0 (arah negatif)

Gambar 11. Perubahan Posisi Keluaran Nozel pada Sumbu $x$ 


\section{KESIMPULAN}

Hasil simulasi dan eksperimental aliran resirkulasi pada updraft gasifier menggunakan ejector memperlihatkan perubahan posisi keluaran nozel ke arah sumbu $x$ negatif dari titik nol akan memberikan peningkatan kecepatan resirkulasi dengan posisi optimum pada posisi keluaran nozel $-3 \mathrm{~cm} \mathrm{~s} / \mathrm{d}$ $-4 \mathrm{~cm}$ dari titik nol (arah sumbu x negatif). Posisi ini adalah posisi yang optimum untuk menarik gas pirolisa yang mengandung tar dalam jumlah lebih besar ke daerah pembakaran agar terjadi proses pengurangan tar.

\section{UCAPAN TERIMAH KASIH}

Penelitian ini merupakan bagian dari hasil penelitian Hibah Penelitian Disertasi Doktor Tahun Anggaran 2010 yang di danai oleh DP2M Ditjend Dikti Kementrian Pendidikan Nasional Republik Indonesia. Dalam kesempatan ini penulis mengucapkan terimah kasih.

\section{DAFTAR PUSTAKA}

1. Bridgwater, A.V., Thermal Processing of Biomass for Fuels and Chemical, Paper, 6 ${ }^{\text {th }}$ Asia-Pacific
International Symposium on Combustion and Energy Utilization, Paper, May 2002.

2. Riffat. S.B., Omer, S.A., CFD Modeling and Experimental Investigation of an Ejector Refrigeration Using Methanol As Working Fluid, Int J Eng Res,25, pp. 115-128, 2001.

3. Pianthong. K., Seehanam, W., Behnia, M., Sriveerakul, T., Investigation and Improvement of Ejector Refrigeration System Using Computational Fluid Dynamics Technique, International Journal of Energy Conversion Management, Vol. 48, Issue 9, pp 2556-2564, 2006.

4. Zhang. Xilai, Jin. Shiping, Huang. Suyi, Tian. Guoqing, Experimental and CFD Analysis of Nozzle Position of Subsonic Ejector. Energy Power Eng, China, Higher Education Press and Springer- Verlag, Vol. 3 (2), pp 167-174, 2009.

5. Sakurop. E Ya, Ejector, Beijing, Science Press, 1977.

6. Xie, W.G., Optimum Length of Injector Mixer, Gas and Head, 17 (6), pp. 15-18, 1997. 